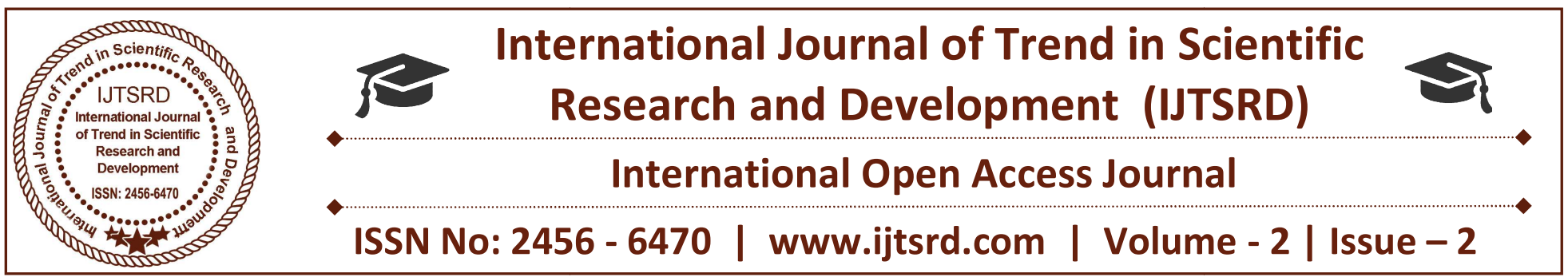

\title{
Experimental Comparison of Yield of Bio-Oil in Fixed Bed Pyrolyzer
}

Rakhesh I P

UG Student, Department of Mechanical Engineering, Stella Mary's College of Engineering, Aruthenganvilai, Tamilnadu, India
Rajkumar S R

A/P, Department of Mechanical Engineering, Stella Mary's College of Engineering, Aruthenganvilai, Tamilnadu, India

\section{ABSTRACT}

Generally all over world, the researchers are researching in the field of renewable energy and alternative fuels. Researchers are working in the manufacturing of bio fuel from the natural material and also scrutiny for the use as alternative energy source. In this work, the research is focused on the extraction of oil by means of fixed bed Pyrolyzer. Also in this paper provides the detailed information about the experimental comparison of yield of bio-oil from the coconut shell and the Indian almond shell with the help of fixed bed pyrolyzer.

Keywords - Coconut Shell, Indian Almond Shell, Pyrolysis, Bio-Oil

\section{INTRODUCTION}

Indian Almond tree is generally found in near coastal areas of the Indian Ocean, through tropical Asia, and into the Pacific Ocean. Indian Almond grow throughout the warmer regions of Indian including Maharashtra, Karnataka, Tamil Nadu, Andra Pradesh and Kerala. It bear fruits during the winter months in India.

Coconut is a popular plantation and is grown in more than 90 countries worldwide. The world production of coconut sums up to around 55 million tonnes annually. Coconut production plays an important role in India. India accounts for 22.34 per cent of the world ${ }^{e e}$ s coconut production and is one of the major players in the world ${ }^{\text {ee }}$ s coconut trade.
Pyrolysis is the process of decomposing organic materials at elevated temperature in the absence of oxygen. The word pyrolysis is derived from the Greek Words "pyro" means fire and "lys" is means separating. It is commonly is used to convert organic material into a solid residue. Pyrolysis is a thermochemical decomposition of organic material at elevated temperatures in the absence of oxygen. It involves the simultaneous change of chemical composition and physical phase, and is irreversible. There are three types of pyrolysis differentiated by the processing time and temperature of the biomass. The types are (i) Slow Pyrolysis, (ii) Flash Pyrolysis, (iii) Fast Pyrolysis

\section{METHODOLOGY}

The basis method which is adopted for the extraction of oil is Pyrolysis method. There are three types of Pyrolysis which are slow, flash \& fast pyrolysis. In our work, the process of extraction of oil is done under the type of Flash Pyrolysis . figure 1 shows about the process involved in the extraction of oil. 


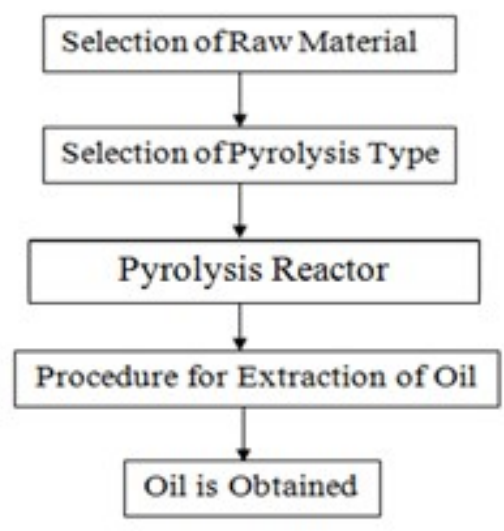

Fig 1: Process chart

\subsection{Selection of Raw Materials}

The raw material which is selected for our work is Coconut shell and Indian almond shell. It is cleaned and the residue of the seed should be removed finely. The nuts of this coconut shell and almond fruit should be removed. Then the coconut shell and Indian almond shell is get dried for more than a month for the removal of moisture nature in the shell. Then it is finely grained by means of crusher or mechanical power.

There are three types of pyrolysis which are slow, flash and fast pyrolysis. In this work, separation of oil from the shell is done by flash pyrolysis. By means of fast pyrolysis, the rapid heating rates and moderate temperature between 400 and $600^{\circ} \mathrm{c}$.

\subsection{Pyrolysis Reactor}

The pyrolysis experiments were conducted in a tubular reactor. An electric heater along with temperature sensing device is fixed in the upper lid which is used to close the reactor. The temperature input is controlled by dimmer-stat. In this reactor water is used as condenser. The temperature which is given at the limit of $500^{\circ} \mathrm{C}$ to $550^{\circ} \mathrm{C}$. The time period which is taken for the combustion of raw material is based on the size and quantity of the material which is provided as input to the reactor.

\subsection{Procedure:}

The input material should be very small less than $5 \mathrm{~cm}$, that in this work selected. Then the material is poured into the fied bed reactor. The input material quantity should more than the half or three-quarters of the capacity of the reactor. So that, the gas which is coming out from the heating shell can leaves out through the condenser. The condensing medium is

water which is allowed to flow over the gas. So that gas is converted into liquid form (i.e) oil and waste gases. The oil is collected in the beaker and the waste gas is removed gradually. In this work, the temperature should gradually increase and maintain the temperature 500 to $550^{\circ} \mathrm{C}$. So that, the yield of oil becomes high.

\section{EXPERIMENTAL COMPARISON}

\subsection{Coconut Shell}

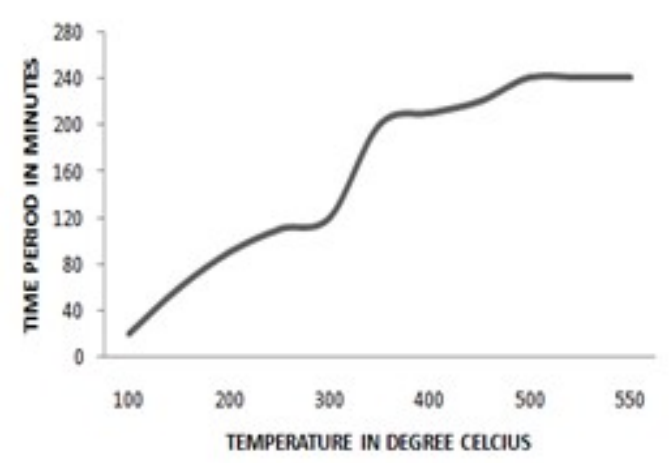

Fig 2: Graph coconut shell: temperature Vs time period for combustion

From the above graph 2, the information provides the time period taken for obtain the desired temperature for the production of oil. The graph is drawn between the temperature versus time period taken for the combustion taken within the reactor. From the graph 3 , shows about the yield value of oil is obtained at certain temperature (i.e) 500 to $550^{\circ} \mathrm{C}$. The graph is drawn versus temperature and yield value.

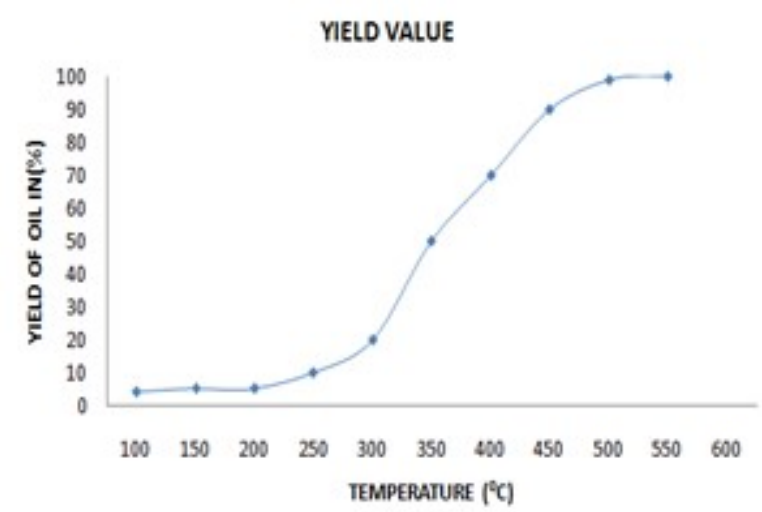

Fig 3: Graph coconut shell: Temperature Vs Yield value Indian almond shell 


\subsection{Indian Almond Shell}

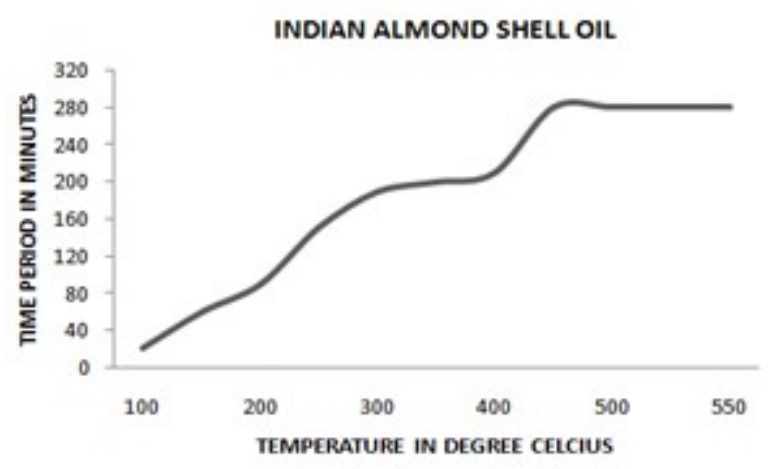

Fig 4: Graph Indian Almond Shell: temperature Vs time period for combustion

\subsection{For Coconut Shell}

Mass of raw material $=2.2 \mathrm{~kg}$

Mass of oil obtained $=1$ litre

Mass of ash $=0.5 \mathrm{~kg}$

Vapour leaves out $=$ remained

\subsection{For Indian Almond Shell}

Mass of raw material $=2.5 \mathrm{~kg}$

Oil obtained $=800 \mathrm{ml}$

Mass of ash obtained $=0.8 \mathrm{~kg}$

Vapour leaves out $=$ remained

\section{RESULTS}

From the experimental comparison the yield of oil from coconut shell is higher than the Indian almond shell oil. The yield of oil is based on the factor of size, quantity and the tendency of material used. In this work the size and the quantity of material which is used is similar. But the nature of material is get varied.

In the future work it will discuss about the nature of material for high and low yield of oil for the Coconut shell and Indian Almond shell respectively.

\section{REFERENCES}

1. Peter A. (2009). "Biomass Pyrolysis Processes: Review of Scope, Control and Variabiliry." UK Biochar Research Centre, 5.

2. A.V. Bridgwater, S. Czermik, "The status of biomass fast pyrolysis. In Fast Pyrolysis of Biomass," Ed. CPL Press: Newbury, UK, vol 2, 2002

3. Tritti Siengchum, Mathew Isenberg, Steven S.C. (2013). "Fast pyrolysis of coconut biomass - An FTIR study." Fuel, 105, 559-565.

4. Faisal Abnisa, W.M.A. Wan daud, W.N.W. Husin, J.N. Sahu (2011). "Utilization possibilities of palm shell as a source of biomass energy in Malaysia by producing bio-oil in pyrolysis process." Biomass Bioener., 35, 1863-1872. 
5. F.G. Hasan (2002). "The production and evaluation of bio-oils from the pyrolysis of sunflower-oil cake," Biomass and bioenergy, 23, 307-314.

6. W.T Tsai (2006). "Fast pyrolysis of rice straw, sugarcane bagasse and coconut shell in an induction-heating reactor." J. Anal. Appl. Pyrolysis., 76, 230-237.

7. S. Sensoz (2006). "Bio-oil production from soybean (Glycine max L.); fuel properties of Biooil," Industrail Crops and Products, 23, 99-105.

8. L. Siyi (2013). "Bio-oil production by pyrolysis of biomass using hot blast furnace slag," Renewable Enegy, 50, 373-377.

9. W. Huang, "Production of light olefins by catalytic conversion of lignocellulosic biomass with HZSM-5 zeolite impregnated with 6 wt.\% lanthanum," Bioresource Technology 121, 2012, pp. 248-144.

10. Faisal Abnisa, W.M.A. Wan daud, W.N.W. Husin, J.N. Sahu (2011). "Utilization possibilities of palm shell as a source of biomass energy in Malaysia by producing bio-oil in pyrolysis process.” Biomass Bioener., 35, 1863-1872.

11. Natthagritt P. Organic liquid productefrom catalytic cracking of refined palm oil. The 5th PSU-UNS International Conference on Engineering and Technology (ICET), Phuket, May 2-3, 2011. Prince of Songkla University, Faculty of Engineering Hat Yai, Songkhla, Thailand 90112.

12. Myers RH. Montgomery DC. Anderson-Cook CM. Response surface methodology. Process and product optimization using designed experiments. 3rd ed. John Wiley \& Sons, Inc.; 2009.

13. J.T. Alberto, Weihong Yang, Wlodzimierz Blasia, "Pyrolysis characteristics and global kinetics of coconut and cashew nut shells," Fuel Processing Technology, vol 87, pp. 523-550, 2006.

14. Abdullah, N. and H. Gerhiouser, 2008. Bio-oil derived from empty fruit bunches. Fuel 87: 26062613

15. Slow pyrolysis of banana culture waste: leaves and pseudostem e. r. k. Fernandes1, C. Marangoni1, 2, S. H. W. Medeiros1, 2, 3, O. Souza1, 2, 3 and N. Sellin1, 2, 3. 